\title{
Дражирование семян моркови и свеклы - важный элемент ресурсосберегающих технологий
}

\section{С.В.Фефелова, А.М.Меньших, А.В.Янченко}

В статье описаны преимущества дражирования семян перед другими видами предпосевной обработки. Раскрыта суть метода и технологический процесс изготовления драже. Применение дражирования в предпосевной обработке семян при возделывании столовой моркови и столовой свеклы, в сравнении с традиционными методами протравливания семян, способствует лучшей удерживаемости препаратов на поверхности семян, положительно влияют на рост и развитие растений столовой моркови и свеклы, что позволяет сократить прямые затраты на дополнительных обработках посевов и снизить пестицидную нагрузку.

Ключевые слова: семена, дражирование, ресурсосберегающие технологии, дражирование семян.

$\mathrm{H}$ а сегодняшний день ресурсои влагосберегающие технологии остаются ведущим направлением при возделывании овощных культур в промышленных масштабах.

Главные принципы ресурсосберегающих технологий:

- минимизация или отказ от механической обработки почвы;

- сохранение растительных остатков на поверхности почвы;

- использование севооборотов, включающих рентабельные культуры и культуры, улучшающие плодородие почв;

- интегрированный подход к контролю вредителей и болезней;

- использование качественных семян, отзывчивых к данным технологиям [1].

Ресурсосберегающая технология предполагает снижение затрат финансовых, энергетических и экологических ресурсов на единицу продукции. Для достижения этого в современном с. - х. производстве разработаны эффективные ресурсосберегающие приемы.

Один из таких приемов - предпосевная подготовка семян. Особый интерес представляет метод дражирования.

Дражирование - это создание вокруг семени специальной оболочки (капсулы), которая содержит в себе питательные, стимулирующие и защитные вещества и обеспечивает унификацию размера и формы семени. Основное отличие и преиму- щество семян с этим видом обработки состоит в том, что для их прорастания требуется значительно меньше влаги. Кроме всего, специальные вещества, включенные в состав капсулы, способствуют удержанию защитных реагентов возле семени.

При дражировании семян, благодаря укрупнению посевного материала, создаются благоприятные условия для точного высева и в силу большей поверхности контакта с почвой семена интенсивней поглощают влагу, при достаточном поливе.

При посеве дражированными семенами увеличиваются благоприятные сроки для развития растений за счет стабилизации температурного режима внутри капсулы определяемого теплоизоляционными свойствами оболочки, что обеспечивает их вызревание, а также повышается их устойчивость к перепаду температур и повышается полевая всхожесть семян растений. Это происходит за счет адресной доставки к семени в период прорастания питательных веществ и микроэлементов оптимального состава и защиты семени от болезней и неблагоприятных природно-климатических условий. Дражирование семян позволяет обеспечить запас питательных веществ, влаги и воздуха, необходимый на каждой стадии образования ростка, регулировать начало и скорость формирования корневой системы и развития ростка [2], а также сократить расход питательных ве- ществ и средств химической защиты растений [3]. Кроме того, дражирование семян позволяет учесть особенности каждого вида растений при выборе состава питательной смеси [4] и варьировать свойства оболочки в зависимости от состава почвы и природных условий [5], что обеспечивает развитие растений на любых почвах благодаря наличию в оболочке значительного количества питательных веществ и возможностью регулирования влагоемкости капсулы [5]. Точное внесение питательных веществ в почву исключает опасность их перераспределения при дожде и сносе ветром [2]. Дражирование семян позволяет обеспечить незначительный расход питательных веществ и средств химической защиты растений в сравнении со сплошной или ленточной обработкой посевов, а также обеспечить защиту семени от болезней и неблагоприятных природно-климатических условий [2].

Известны различные способы дражирования семян в виде драже путем нанесения на поверхность семени искусственных одно- и многослойных оболочек из различных материалов, которые стимулируют прорастание, обогащают растение питательными веществами, предохраняют от поражения болезнями и вредителями [1].

Технологический процесс изготовления драже идет в соответствии с одним из двух принципов:

- дражирование наслаиванием;

- прессование гранул.

Прессование гранул могут применять в производственных масштабах, но недостаток гранул - неравномерная толщина оболочки вокруг семени. Создание искусственной оболочки путем наслаивания делает ее более равномерной и многослойной. Это особо важно при включении в оболочку нескольких препаратов которые необходимо наносить послойно. Недостаток этого метода формирования искусственной оболочки - высокая трудоемкость созда- 


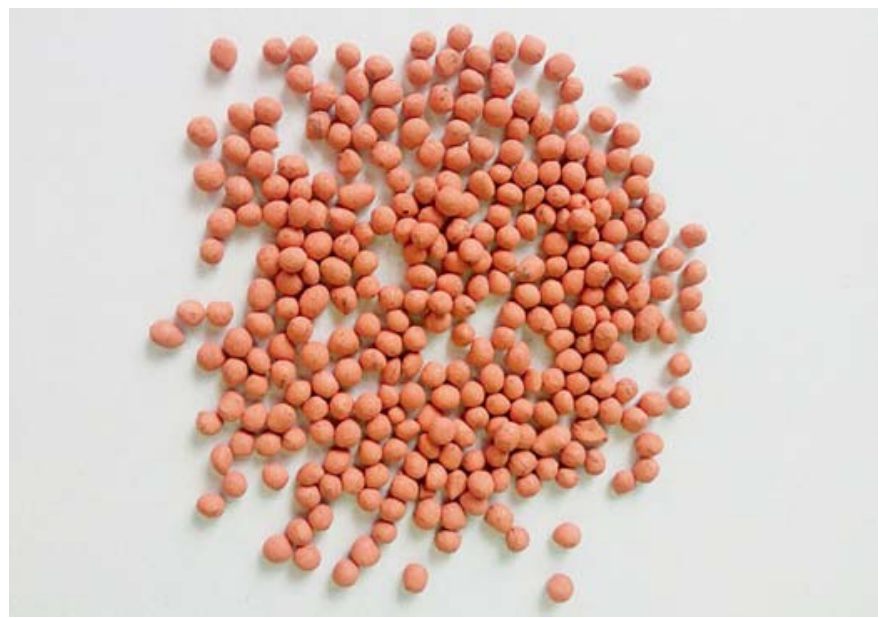

Рис. 1. Капсулированные семена свеклы столовой

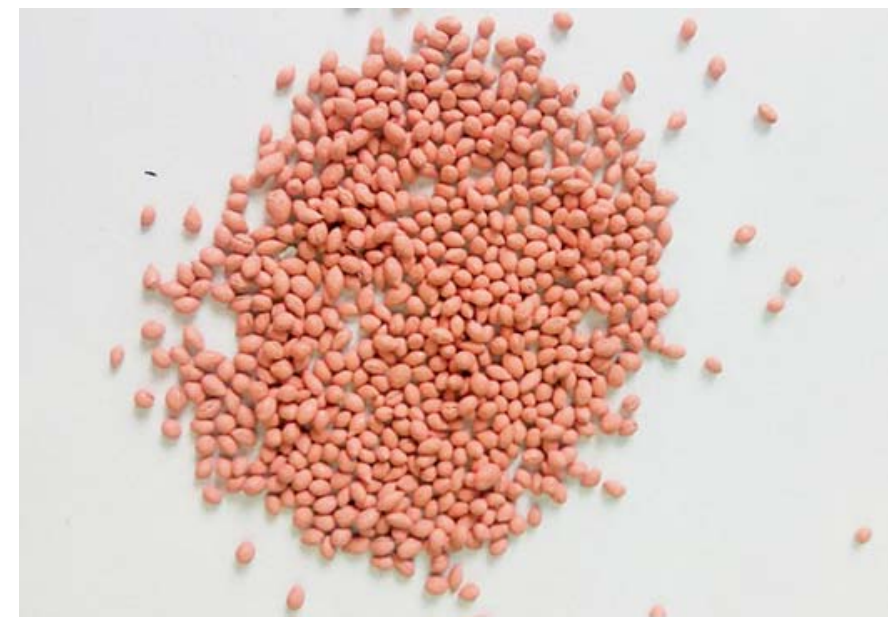

Рис. 2. Капсулированные семена моркови столовой ния, и точное соблюдение технологических регламентов.

Существует два способа создания капсул наслаиванием.

Гравитационный. За счет гравитации заставляют вращаться семена по стенке рабочей камеры дражиратора. Существенный недостаток гравитационных дражираторов - низкая производительность, поэтому в производстве чаще пользуются комплексом батарей.

Динамический. Семенам придается ускорение за счет центробежной силы. Ускоренный поток семян попадает на неподвижную поверхность рабочей камеры, в результате семена начинают вращаться и на них наносятся препараты, за счет выдвижения лопастей семена попадают обратно на вращающуюся поверхность, где получают вновь ускорение.

В 2008-2011 годы Всероссийским НИИ овощеводства совместно с ОАО ГСКБ «Зерноочистка» г. Воронежа был разработан более совершенный инкрустатор-дражиратор динамического типа ИД-10.

Инкрустатор-дражиратор ИД10 динамического типа работает на высоких оборотах (400-900 оборотов в минуту). Здесь семена и масса для дражирования семян подаются на быстро вращающийся ротор, который их разгоняет за счет действия центробежных сил. С тарелки ротора частицы попадают на неподвижную цилиндрическую поверхность и, сталкиваясь с отражателем, снова возвращаются в тарелку ротора. Этим способом формируются более выровненные по размерам драже, возможно использование относительно легких, пористых материалов, обеспечивающих сохранение высоких посевных качеств семян в лабораторных и полевых условиях.

В результате проведенных исследований установлены оптимальные режимы работы инкрустатора-дра-

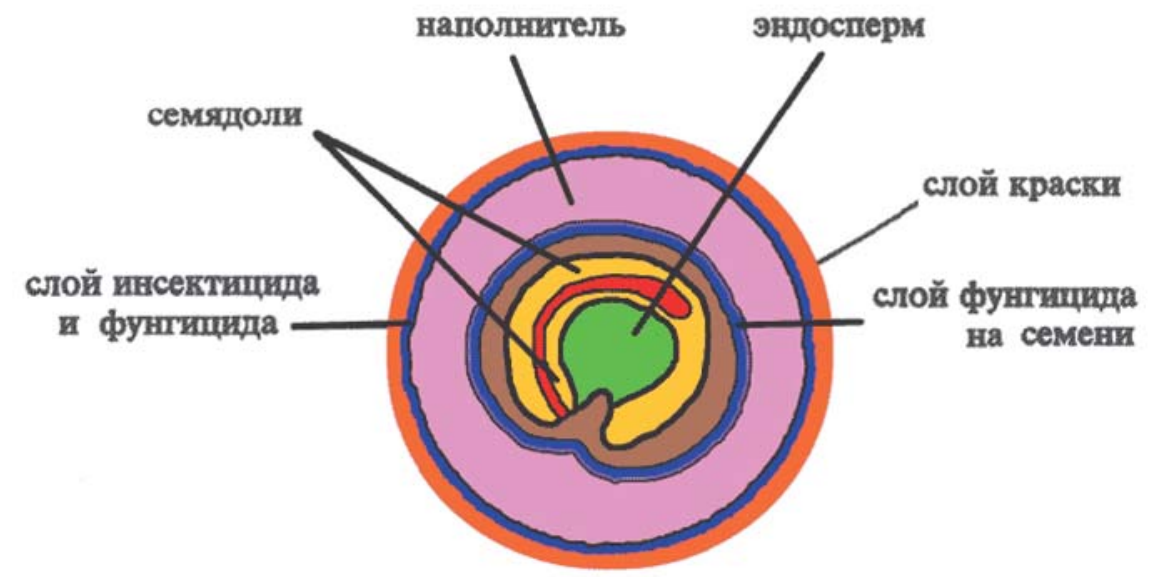

Рис. 3. Схема разреза капсулированного семени свеклы столовой жиратора динамического типа ИД-10 для предпосевной подготовки семян столовой моркови и столовой свеклы. Скорость вращения ротора при дражировании составляет 700-900 оборотов в минуту, для инкрустации необходимо 600-700. Оптимальное количество семян столовой моркови, подаваемое в рабочую камеру, составляет 0,5 кг при дражировании и 2,0 кг при инкрустировании. Подача компонентов в рабочую камеру при инкрустации семян происходит последовательно по 15 мл ТМТД и глазури. При дражировании подача компонентов в рабочую камеру периодически последовательно 4 мл ТМТД, 3 раза по 100 г наполнителя Covercoat VE и 30 мл воды, 3 раза по 200 г наполнителя Covercoat VE и 60 мл воды, 18 раз по 500 г наполнителя Covercoat VE и 150 мл воды, 170 мл глазури.

На рисунках 1 и 2 изображены семена дражированные динамическим способом наслаивания капсул.

В связи с наблюдаемыми в последние годы массовыми поражениями овощных растений вредителями и болезнями, большой практический интерес представляет разработка приемов защиты растений путем предпосевного дражирования семян с включением новых адаптивных препаратов в оболочку обработанных семян.

Дражирование имеет большие преимущества перед другими способами протравливания, позволяет получить ряд положительных эффектов, в частности, обеспечивает:

выравненность технологических свойств семян, имеющих в исходном состоянии чрезвычайное разнообразие как по форме и размерам, так и по состоянию поверхности; 


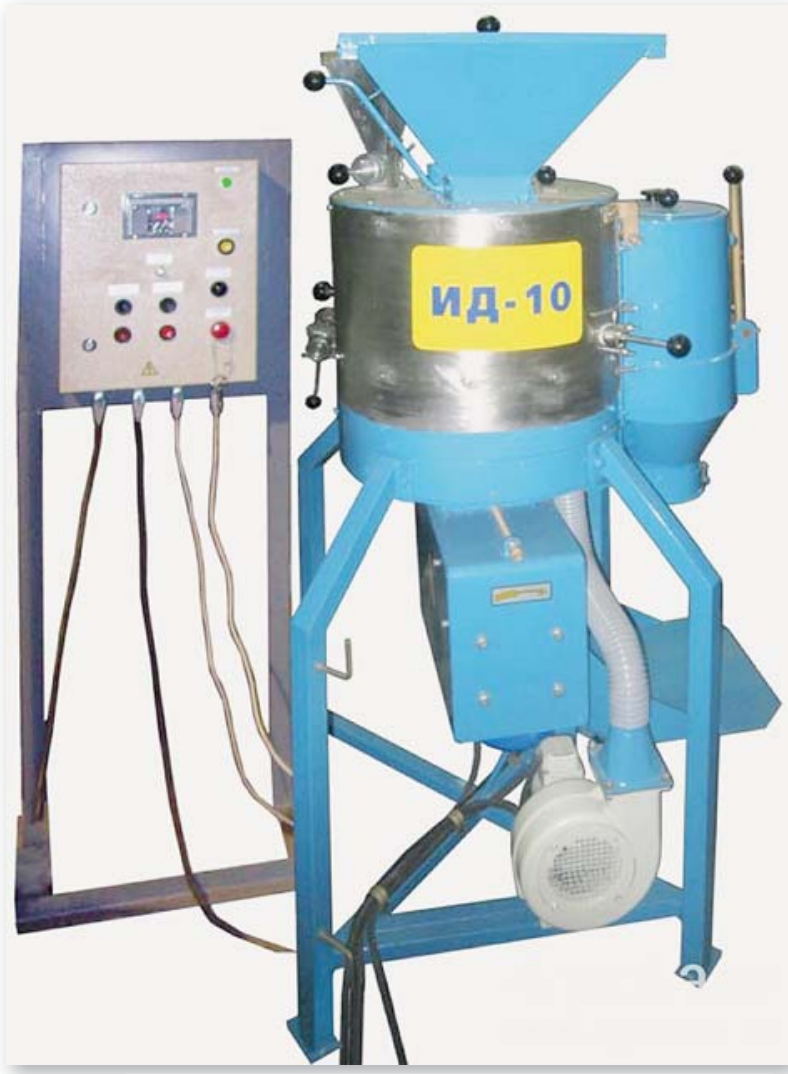

Рис. 4. Инкрустатор-дражиратор динамического ИД-10
Библиографический список

1.Янченко А.В. Приемы повышения качества корнеплодов столовой моркови на аллювиальных среднесуглинистых почвах нечерноземной зоны: дисс. канд. с. - х. наук. М.: ВНИИо, 2008. 111 с.

2.Янченко А.В. Агротехнические приемы получения экологически безопасных корнеплодов моркови // Картофель и овощи. 2008. №3. С. $15-16$

3.Перспективные препараты для инкрустирования семян столовых корнеплодов / Ю.А. Быковский, А.В. Янченко, М.И. Азопков, В.С. Голубович, С.В. Фефелова, Р.А. Багров // Картофель и овощи. 2018. № 5. C. 16-19.

4.Фефелова С.В., Шайманов А.А., Янченко А.В. Влияние предпосевной обработки семян столовой моркови плазмой на полевую всхожесть и урожайность.. Сборник научных трудов по материалам Международной научно-практической конференции, посвященной VII Квасниковским чтениям. 2016. С. 304-308.

5.Шайманов А.А., Янченко А.В. Предлагаем комплекс машин для предпосевной подготовки семян // Картофель и овощи. 2008. №2. С. 23.

\section{Об авторах}

Фефелова Светлана Владимировна, канд.

c. - х. наук, с.н.с. отде-

- доступ непосредственно к семени, а позже к корню растений питательных веществ - микроэлементов и стимуляторов роста;

- подачу пестицидов, обеспечивающих защиту молодого растения в первый период жизни от заболеваний, вредителей и сорняков;

- эффективную защиту проростка от вредителей и болезней непосредственно в зоне его развития;

- значительно меньший расход пестицида (что способствует меньшему загрязнению окружающей среды) и значительное снижение затрат за счет сокращения числа подкормок и междурядных обработок (например, 150 г д.в. (действующего вещества) /га инсектицидов, включенных в дражировочную смесь, соответствуют 5000 г д.в/га инсектицидов, вносимых в почву в виде гранулятов);

- округлую форму и размеры мелких семян и семян неправильной формы.

Дражированные семена можно высевать поштучно, это позволяет сократить расход посевного материала, устраняет конкуренцию растений, возникающую из-за близкого расположения при обычном севе, и снижает необходимость прореживания.

Анализ публикационной активности журнала:

Общее число статей в РИНЦ.....

Пятилетний импакт-фактор РИНЦ филиал Федерального государственного бюджетного научного учреждения «Федеральный научный центр овощеводства».

Encapsulation of seeds is an important element of resource-saving technologies

S.V. Fefelova, $P$ hD, senior research

fellow, department of technologies and innovations Tel.: +7 (916) 463-04-20. Email: babichsv7@yandex.ru

A.M. Menshikh, PhD, leading research fellow, head of department of technologies and innovations. . Tel.: +7 (916) 750-21-37.

E-mail: soulsunnet@gmail.com.

A.V. Yanchenko, PhD, leading research fellow, head of laboratory of mechanization of seed growing, department of

technologies and innovations. Тел.: +7 (916) 380-32-81. E-mail: laboratoria2008@ yandex.ru

Summary: The article describes the advantages of seed encapsulation over other types of pre-sowing treatment. The essence of the method and the technological process of making dragees are revealed. Modern technology of production of vegetable crops provides for a high yield with high quality products. Increasing the yield of table root crops is possible through the use of new high-yielding varieties and hybrids, and reduce the non-standard part of the crop. The use of encapsulation in pre-sowing seed treatment in the cultivation of table carrots and table beets, in comparison with traditional methods of seed treatment, provides better retention of drugs on the surface and give a more positive effect on the intensive growth and development of plants of table carrots and beets, which reduces the direct costs of additional processing of crops and reduce the pesticide load on the crop.

Keywords: seeds, seed encapsulation, resource-saving technologies, seed pelleting, advantages of encapsulation, capsule manufacturing process.

\section{Журнал «Картофель и овощи» в наукометрической базе электронной библиотеки eLIBRARY.RU}

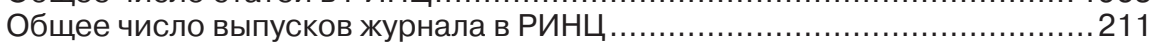

Суммарное число цитирований журнала в РИНЦ ............................. 10288

Место в общем рейтинге SCIENCE INDEX за 2017 год.............................. 1585

Место в рейтинге SCIENCE INDEX за 2017 год по тематике

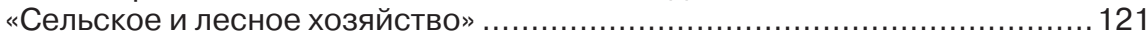

Место в рейтинге по результатам общественной экспертизы ................1285 0,404 